\title{
A model for co-expression pattern analysis of genes implicated in angiogenesis and tumour cell invasion in cervical cancer
}

\author{
PO Van Trappen*,', A Ryan', M Carroll'2, C Lecoeur ${ }^{3}$, L Goff', VG Gyselman', BD Young ${ }^{4}$, DG Lowe ${ }^{6}$, \\ MS Pepper', JH Shepherd' and IJ Jacobs'
}

\begin{abstract}
'Department of Gynaecological Oncology, Cancer Research UK Translational Oncology Laboratory, John Vane Science Centre, St. Bartholomew's and the Royal London School of Medicine and Dentistry, Queen Mary University of London, Charterhouse Square, London ECIM 6BQ, UK; ${ }^{2}$ Department of Nuclear Medicine, St. Bartholomew's and the Royal London School of Medicine and Dentistry, Queen Mary University of London, London ECIA 7BE, UK; ${ }^{3}$ Genome Centre, St. Bartholomew's and the Royal London School of Medicine and Dentistry, Queen Mary University of London, Charterhouse Square, London ECIM 6BQ UK; ${ }^{4}$ Cancer Research UK Medical Oncology Laboratory, St. Bartholomew's and the Royal London School of Medicine and Dentistry, Queen Mary University of London, Charterhouse Square, London ECIM 6BQ, UK; ${ }^{5}$ Academic Department of Surgery, St. Bartholomew's and the Royal London School of Medicine and Dentistry, Queen Mary University of London, London ECIA 7BE, UK; ${ }^{6}$ Academic Department of Histopathology, St. Bartholomew's and the Royal London School of Medicine and Dentistry, Queen Mary University of London, London ECIA 7BE, UK; ${ }^{7}$ Department of Morphology, University Medical Centre, Geneva, Switzerland.
\end{abstract}

To date, numerous genes have been identified which are involved in both tumour neovascularisation (angiogenesis) and tumour cell invasion, and most of them are also expressed to some extent under normal physiological conditions. However, little is known about how these genes co-express in these settings. This study was undertaken to quantitate mRNA levels in normal and malignant cervical tissues of nine selected genes $\left(V_{E G F}{ }_{121}, V_{E G F}{ }_{165}, V E G F_{189}\right.$, VEGF-C, elF-4E, b-FGF, TSP-2, MMP-2 and MMP-9) implicated in the above processes using real-time quantitative RT-PCR. In addition, the Spearman's rank correlation was used to determine their co-expression patterns. The transcript levels for the different VEGF-A splice variants $\left(V E G F_{121}, V E F_{165}, V E G F_{189}\right)$ were at least 10 -fold higher in the cancer cases, with the highest levels in the primary tumours demonstrating lympho-vascular space involvement. The lymphangiogenic factor VEGF-C and MMP-9 were upregulated I30and 80-fold respectively in cervical cancers. The highest levels of VEGF-C mRNA were found in the lymph-node positive group. The transcript levels for b-FGF were similar in normal cervical tissue and early-stage cervical cancer, however, higher levels were found in the cervical cancers with advanced stage disease. Comparing gene transcript levels between recurrent and non-recurrent cervical cancer patients revealed significant differences $(P=0.038)$ in transcript levels for the angiogenesis inhibitor TSP-2, with the highest levels in non-recurrent cases. Co-expression pattern analysis in normal cervical tissue revealed highly significant co-expressions $(P<0.000 \mathrm{I})$ between TSP-2 and most other genes analysed $\left(V E G F_{121}, V E G F_{165}, V E G F-C, b-\right.$ FGF and MMP-2). In cervical cancer, TSP-2 appears only to be highly co-expressed with MMP-2 $(P<0.000 \mathrm{I})$. In contrast to normal cervical tissue, we found a highly significant co-expression $(P<0.000 \mathrm{I})$ between MMP-9 and $V \mathrm{GGF}_{189}$ in cervical cancer. The combined application of real-time quantitative RT-PCR and Spearman's rank correlation identifies gene transcripts which are simultaneously co-expressed. Our results revealed a significant co-expression between the angiogenesis inhibitor TSP-2 and most other genes analysed in normal cervical tissue. In cervical cancer, we found a strong upregulation of VEGF-C and MMP-9 mRNA, with a highly significant co-expression between MMP-9 and VEGF 189.

British Journal of Cancer (2002) 87, 537-544. doi:10.1038/sj.bjc.660047I www.bjcancer.com

(c) 2002 Cancer Research UK

Keywords: cervical cancer; angiogenesis; tumour cell invasion; co-expression pattern analysis

During tumour progression, two phases can be recognised with regard to neovascularization: a prevascular and a vascular phase. The transition from one phase to the other is referred to as the 'angiogenic switch' (Folkman, 1971, 2000; Carmeliet and Jain, 2000; Hanahan and Folkman, 1996). The current working hypothesis is that the 'switch' involves either the induction of a positive regulator and/or the loss of a negative regulator. In the healthy adult organism, endothelial cell turnover is very low. This is

*Correspondence: PO Van Trappen; E-mail: p.o.vantrappen@qmul.ac.uk. Received 23 November 200I; revised 15 May 2002; accepted 23 May 2002 thought to be due to the dominance of endogenous negative regulators, since positive regulators are frequently detected in adult tissues in which there is apparently no angiogenesis. Endogenous negative regulators identified to date include members of the thrombospondin (TSP) family, angiostatin and endostatin (Volpert et al, 1995; O’Reilly et al, 1994, 1997). Among the positive endogenous regulators of tumour angiogenesis are the vascular endothelial growth factor (VEGF) and fibroblast growth factor (FGF) families of cytokines.

Molecular cloning has revealed at least five different isoforms of VEGF which are generated from a single mRNA by alternative splicing, and which have significantly different biochemical features and biological effects (Ferrara et al, 1991; Houck et al, 1991; Veik- 
kola and Alitalo, 1999; Yancopoulos et al, 2000). There is recent evidence in breast cancer patients that levels of VEGF-A mRNA correlate with mRNA levels of the translation initiation factor eIF-4E, implying co-regulation of these genes (Scott et al, 1998). In several cancer types (breast, head and neck and prostate cancer) eIF-4E causes increased translational efficiency of several oncogene transcripts (e.g. cyclin D1 and c-Myc) and growth factors (e.g. basic-FGF and VEGF), leading to overexpression of their products (De Benedetti and Harris, 1999). Recent studies have shown that the growth factor VEGF-C plays a crucial role in the growth of lymphatic vessels (lymphangiogenesis), an effect which is mediated in part through VEGFR-3 (Jeltsch et al, 1997; Lymboussaki et al, 1998).

Many biological processes, including angiogenesis and tumour cell invasion, require extracellular proteolysis for degradation of the extracellular matrix. This allows endothelial and tumour cells to migrate through tissue stroma and subsequently to enter and spread via the blood and/or lymphatic systems. The matrix metalloproteinases (MMPs), including MMP-2 and MMP-9 (gelatinase$\mathrm{A}$ and $-\mathrm{B}$ ), are amongst the best studied proteases in this respect. Enhanced mRNA and protein levels of both MMP-2 and MMP-9 have been detected in breast, colon and pancreatic cancer (Campo et al, 1992). A recent study in transgenic mice suggests that MMP9 triggers the angiogenic switch during carcinogenesis (Bergers et al, 2000).

Until recently, studies on angiogenesis in several cancers have largely been limited to analysis of microvascular density (MVD). However, little information is available regarding the co-expression of genes implicated in angiogenesis in different tumour types. Both angiogenesis and lymphangiogenesis are likely to be key processes in disease progression in cervical malignancy, given the well documented pattern of direct spread through parametrial tissues, lymphatic spread to pelvic lymph nodes, and haematogenous dissemination to distant organs. We have recently shown that approximately $50 \%$ of early-stage cervical cancers shed tumour cells to the pelvic lymph nodes (Van Trappen et al, 2001). The lymphangiogenic factor VEGF-C may be a key element in this process.

Recent technical advances have provided us with opportunities to assess levels of gene transcription and to identify patterns of co-expression. Although microarray technology can measure the expression of thousands of genes simultaneously, it is a semi-quantitative technique (Schena et al, 1995; Eisen et al, 1998; Duggan et al, 1999; Lander, 1999; Liotta and Petricoin, 2000). As the genes involved in tumour angiogenesis are also expressed in normal tissues, a real understanding of gene expression in carcinogenesis requires an accurate and fully quantitative technique. Real-time quantitative RT-PCR fulfils this requirement and has recently been used to accurately quantitate transcription levels of a variety of genes (Heid et al, 1996).

The aim in our study was to identify which genes are coexpressed in tumours in which angiogenesis and/or lymphangiogenesis are prominent, and to determine whether a different coexpression pattern exists between normal and malignant cervical tissue. Transcripts of the following nine genes were analysed: VEGF $_{121}$, VEGF $_{165}$, VEGF $_{189}$, VEGF-C, eIF-4E, basic-FGF (bFGF), TSP-2, MMP-2 and MMP-9.

\section{MATERIALS AND METHODS}

\section{Patients and samples}

The patient population consisted of 52 women of whom 34 had malignant and 18 normal cervical tissue. Ethical approval was obtained from the Local Research Ethics Committee of the East London and City Health Authority. During the period between January 1998 to March 2000, radical hysterectomy and pelvic lymphadenectomy were carried out in 29 cervical cancer patients with early-stage disease confined to the uterus. Five patients were treated with primary radiotherapy for advanced stage disease (stage IIB - III) during the same time period, and cervical biopsies were taken before radiotherapy. None of the cancer patients had undergone any previous treatment to the cervix. Tissue specimens were taken from the periphery of the tumour, as it is known that neovascular hot spots occur predominantly at tumour margins (Tokumo et al, 1998). One portion was snap frozen for RTPCR analysis while a neighbouring portion was fixed in $10 \%$ formaldehyde for histological examination to determine whether the biopsy specimen contained $>80 \%$ tumour tissue. The histological cell types of the 34 cervical cancers were assigned according to the World Health Organisation (WHO) classification: 23 were classified as squamous cell carcinoma, 8 as adenocarcinoma, 2 as clear cell carcinoma and 1 as carcinoid. Clinical staging was determined using the International Federation of Gynaecology and Obstetrics (FIGO) classification: 6 were stage IA2, 15 were staged as stage IB1, 6 were stage IB2, 2 were stage IIA, 3 were stage IIB, 2 were stage III (Table 1: patient characteristics).

As controls, 18 biopsy specimens were obtained from normal cervices from patients who underwent a simple hysterectomy for non-malignant lesions in the corpus of the uterus. None of these patients had conditions, such as endometriosis, in which angiogenesis may be an important component. Light microscopic examination confirmed the normal histology.

\section{RNA extraction}

Total RNA was extracted from all samples using the acid-guanidinium isothiocyanate-phenol-chloroform method as described previously (Chomczynski and Sacchi, 1987). Disintegration of the tissue was achieved by vortexing and by using a Dounce homogeniser. The RNA samples were stored in $50 \mu$ l diethyl pyrocarbonate (DEPC) treated distilled water at $-80^{\circ} \mathrm{C}$. RNAs were further purified using an RNeasy Mini Protocol for RNA Clean up (Qiagen Ltd., Crawley, UK) and quantitated in a Genequant spectrophotometer (Pharmacia, St Albans, UK).

Table I Clinicopathological characteristics of the 34 patients whose cervical cancers were analysed for expression of nine genes implicated in angiogenesis

\begin{tabular}{lc}
\hline Patient characteristics & Number \\
\hline Cell type (WHO-classification) & \\
Squamous cell carcinoma & 23 \\
Adenocarcinoma & 8 \\
Clear cell carcinoma & 2 \\
Carcinoid & 1 \\
Histological grade & 15 \\
Grade I & 14 \\
Grade 2 & 5 \\
Grade 3 & \\
FIGO-stage & 6 \\
Stage IA2 & 15 \\
Stage IBI & 6 \\
Stage IB2 & 2 \\
Stage IIA & 3 \\
Stage IIB & 2 \\
Stage III & \\
Lymph nodes & $6 / 28$ \\
Positive/negative & \\
Lympho-vascular space invasion & $9 / 25$ \\
Positive/negative & \\
Recurrent disease during follow-up & $6 / 28$ \\
Positive/negative & \\
\hline
\end{tabular}




\section{Primers and probes}

Primers and probes were designed using Primer Express software (PE-ABI). The probes were designed specifically to span an intron in order to avoid potential amplification of small amounts of contaminating DNA in the analysed samples. The probes were labelled at the $5^{\prime}$ end with 6-carboxy fluorescein (FAM) and at the $3^{\prime}$ end with 6-carboxy-tetramethyl rhodamine (TAMRA). Primers and probes were stored at $-20^{\circ} \mathrm{C}$ until use. Table 2 shows the primers and probe sequences for: VEGF 121 (GenBank accession no: M27281), VEGF 165 (GenBank accession no: M27281), VEGF 189 (GenBank accession no: M27281), VEGF-C (GenBank accession no: X94216), eIF-4E (GenBank accession no: NM001968), TSP-2 (GenBank accession no: L12350), b-FGF (GenBank accession no: M27968), MMP-2 (GenBank accession no: M58552), MMP-9 (GenBank accession no: NM004994), and GAPDH (GenBank accession no: G04038).

\section{Single-step real-time quantitative RT - PCR}

Real-time quantitative RT-PCR analysis was performed using the Taqman PCR Core Reagent Kit (PE Biosystems). Prior to reverse transcription, the RNA template was heated for $2 \mathrm{~min}$ at $50^{\circ} \mathrm{C}$ in the presence of $0.01 \mathrm{U} \mathrm{l}^{-1}$ uracil $\mathrm{N}$-glycosylase. To prevent carry-over of contaminating DNA, the reaction was carried out in the presence of dUTP. Total RNA (100 ng) was reverse transcribed in a $25 \mu \mathrm{l}$ reaction mixture at $60^{\circ} \mathrm{C}$ for $30 \mathrm{~min}$. After 5 min denaturation at $92^{\circ} \mathrm{C}$, PCR was carried out for 40 cycles with denaturation at $92^{\circ} \mathrm{C}$ for $20 \mathrm{~s}$ and extension at $62^{\circ} \mathrm{C}$ for $60 \mathrm{~s}$ in the presence of the fluorescent oligonucleotides indicated above. RT-PCR analyses were carried out at least twice for each gene transcript to determine consistency of results, and GAPDH mRNA was assessed as internal control for RNA quality. Reactions were recorded and analysed using the ABI 7700 Prism Sequence detection system (Perkin-Elmer Applied Biosystems, Warrington, UK). Accurate quantitation was achieved through the generation of standard curves by serially diluting a known amount of cDNA from corresponding synthetic RNA and performing Taqman PCR on the series alongside patient samples. All gene transcript levels are expressed per $\mu \mathrm{g}$ of RNA.

\section{Preparation of cDNA}

Two $\mu \mathrm{g}$ of DNase treated RNA was mixed with $2 \mu \mathrm{l}(1 \mu \mathrm{g})$ of random hexamers in DEPC water, in a total volume of $14 \mu \mathrm{l}$. The mixture was heated at $75^{\circ} \mathrm{C}$ for $15 \mathrm{~min}$ and cooled on ice for $5 \mathrm{~min}$. Subsequently, $5 \mu \mathrm{l}$ of M-MLV RT reaction buffer, $5 \mu \mathrm{l}$ of nucleotide pool and $1 \mu \mathrm{l}$ of M-MLV RT enzyme was added. This mixture was left at room temperature for $10 \mathrm{~min}$ and incubated at $40^{\circ} \mathrm{C}$ for $50 \mathrm{~min}$. Seventy five $\mu \mathrm{l}$ of DEPC water was added to make up a total volume of $100 \mu \mathrm{l}$.

\section{Real-time PCR for 18S rRNA}

The housekeeping gene 18S rRNA was evaluated in all samples as internal control. In a total volume of $25 \mu \mathrm{l}$ the following was added as reaction mixture: $12.5 \mu \mathrm{l}$ of TaqMan Universal Master Mix (Applied Biosystems), $2.5 \mathrm{ul}$ of human 18S rRNA Assay Reagents (Pre-developed; Applied Biosystems), $1 \mathrm{ul}$ (100 ng) of cDNA and $9 \mu \mathrm{l}$ of DEPC water. After $2 \mathrm{~min}$ at $50^{\circ} \mathrm{C}$, denaturation was performed at $95^{\circ} \mathrm{C}$ for $10 \mathrm{~min}$; PCR was carried out for 40 cycles with denaturation at $95^{\circ} \mathrm{C}$ for $15 \mathrm{~s}$ and annealing at $60^{\circ} \mathrm{C}$ for $1 \mathrm{~min}$. The threshold cycle $(\mathrm{Ct})$ for each sample was determined.

\section{Statistical Analysis}

The Mann-Whitney $U$-test was used to compare the means of the gene expressions between normal and malignant tissues (SPSS software, Version 9.0 for Windows, SPSS, Inc, Chicago, IL, USA). We have used the Spearman's rank correlation to compare the coexpression patterns between the normal and the cancer group. A correlation with a $P$-value of $<0.05$ was considered to be significant. In addition, the $\mathrm{z}$-test was performed to compare the Spearman correlation matrices between normal and malignant (MedCalc, Version 6.0 for Windows, 1998). The two compared correlation coefficients $(r)$ are transformed into two $\mathrm{z}$ values by this formula:

$$
\mathrm{z}=0.5 \times[\ln (1+\mathrm{r}) \quad \ln (1 \quad \mathrm{r})]
$$

which almost follows a normal distribution of mean $\mathrm{m}$, and variance $1 /(n-3)$, with $\mathrm{n}$ the number of individuals in the sample.

Table 2 Primers/probe sequences used in the real-time quantitative RT - PCR assays to analyse transcription levels of nine genes involved in angiogenesis. The housekeeping gene GAPDH was also included.

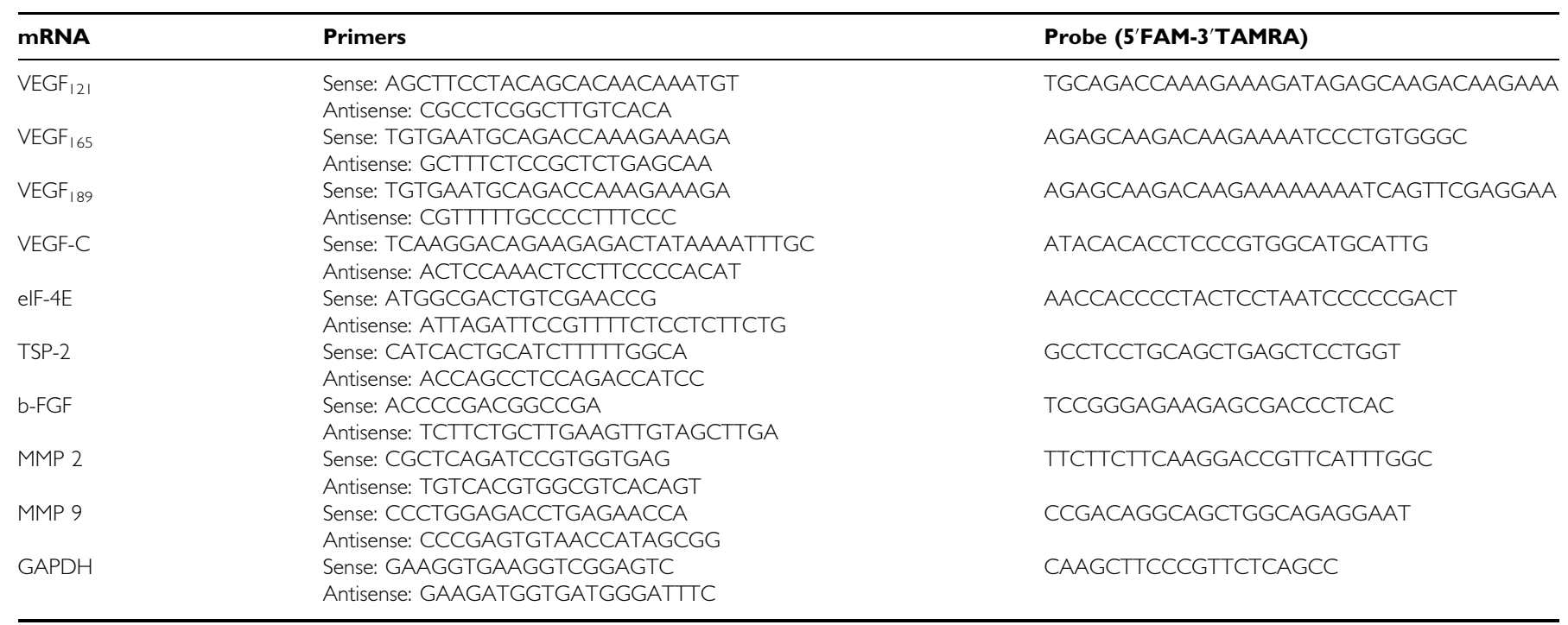


Then, for the statistical value $\mathrm{D} / \mathrm{SD}_{\mathrm{D}}$ a $P$-value is given:

$$
D=z_{1} \quad z_{2} \text { and } \mathrm{SD}_{\mathrm{D}=\sqrt{ }}\left(\text { variance } z_{1}+\text { variance } z_{2}\right)
$$

\section{RESULTS}

\section{Transcript levels in normal and malignant cervical tissue}

Real-time quantitative RT - PCR analysis was performed on mRNA transcripts of nine genes $\left(\mathrm{VEGF}_{121}, \mathrm{VEGF}_{165}, \mathrm{VEGF}_{189}, \mathrm{VEGF}-\mathrm{C}\right.$, eIF-4E, b-FGF, TSP-2, MMP-2 and MMP-9) involved in angiogenesis and/or lymphangiogenesis as well as tumour cell invasion. Experiments were repeated at least twice for each gene. GAPDH was initially considered as an internal control. However, considerable variation in mRNA levels were found for this housekeeping gene. In contrast, all samples showed a threshold cycle between 17 and 18 for $18 \mathrm{~S}$ rRNA, demonstrating its usefulness as internal control for quality of RNA.

Figures 1A, B, C show the transcript levels in normal and malignant cervical tissues for the nine genes analysed. All tumour and normal samples expressed the VEGF-A isoforms in order of decreasing abundance, $165>121>189$ (Figure 1A). In normal cervical tissue, a greater distribution ( $95 \%$ confidence interval (CI)) was observed for the mRNA copy numbers of the different VEGF-A splice variants compared to cervical cancer. This may be due in part to the influence of the hormonal cycle. The levels of the different VEGF-A splice variants were significantly higher in malignant compared to normal cervical tissues. There was an 11fold increase in the mean copy number of $V_{E G F}$ 165, a 23-fold increase in $\mathrm{VEGF}_{121}$ and a 13-fold increase in $\mathrm{VEGF}_{189}$ in malignant compared to normal tissues. The highest levels of $\mathrm{VEGF}_{121}$, VEGF $_{165}$ and VEGF $_{189}$ mRNA were found in cervical tumours with lympho-vascular space involvement in the primary tumour, which is known to be a poor prognostic factor (lympho-vascular space includes all small vessels, capillaries as well as lymphatic vessels, present in the primary tumour and the surrounding tissue). All cervical cancers expressed high levels of VEGF-C, and the levels were more than 130-fold higher than in normal cervical tissues (Figure 1B). The highest levels of VEGF-C mRNA were found in the lymph node-positive group. Of the 18 normal cervical tissues analysed, only 10 expressed $>100$ copies of VEGF-C mRNA/ $\mu \mathrm{g}$ total RNA, suggesting that VEGF-C is not implicated in normal physiological processes in cervical tissue. Levels of b-FGF mRNA were similar in normal cervical tissue and early-stage cervical cancers. However, high levels of b-FGF mRNA were found in the five cervical cancers with advanced stage disease. The levels of TSP-2 and of eIF-4E mRNA were increased four- and seven-fold respectively in cervical cancer. No differences in the level of MMP-2 mRNA were found between normal and malignant cervical tissue. However, an approximately 80-fold increase in MMP-9 mRNA was observed in cervical cancers (Figure 1C).

Using the Mann-Whitney $U$-test the differences in the means between the two groups (normal $v s$ cancer) are highly significant $(P$-values $\leqslant 0.006)$, except for the genes b-FGF and MMP-2 (respective $P$-values: $0.336,0.584$ ) (Figure $1 \mathrm{~A}, \mathrm{~B}, \mathrm{C}$ ).

\section{Gene co-expression patterns in normal and malignant cervical tissue}

Tables $3 \mathrm{~A}$ and $\mathrm{B}$ show the Spearman correlation matrices of gene co-expressions (with rho and $P$-values) in normal and malignant cervical tissue. In normal cervical tissue, a strong co-expression is observed between the angiogenesis inhibitor TSP-2 and the other genes analysed. Furthermore, MMP-2 is also strongly co-expressed with the other genes analysed in normal cervical tissue, except for MMP-9. In cervical cancer, TSP-2 seems to be strongly co-
A

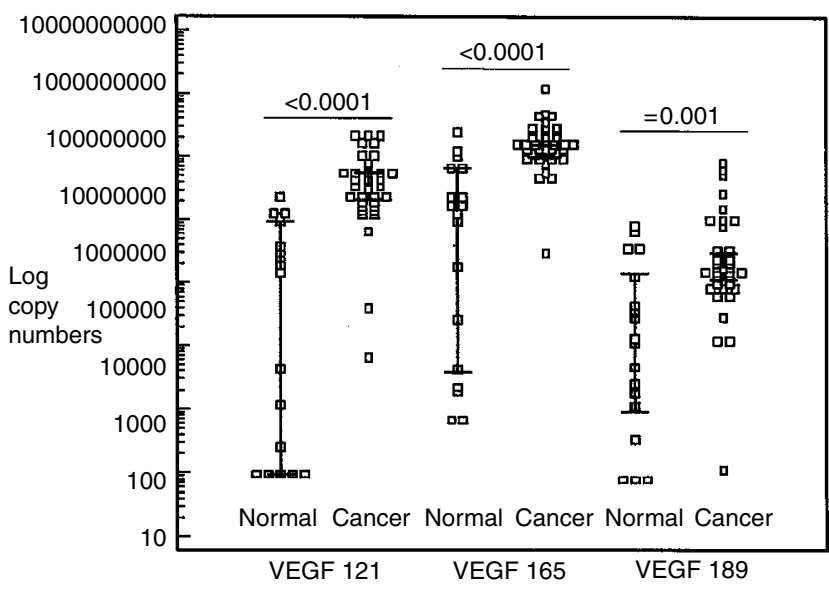

B

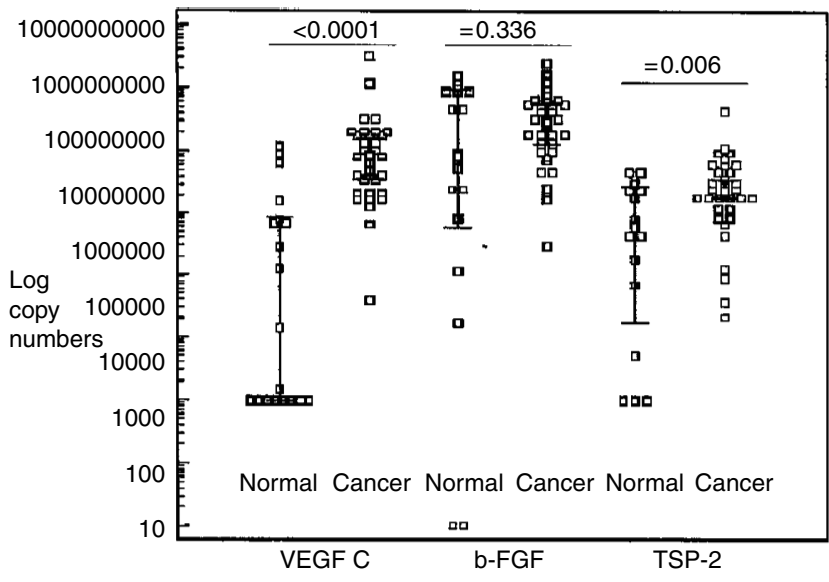

C

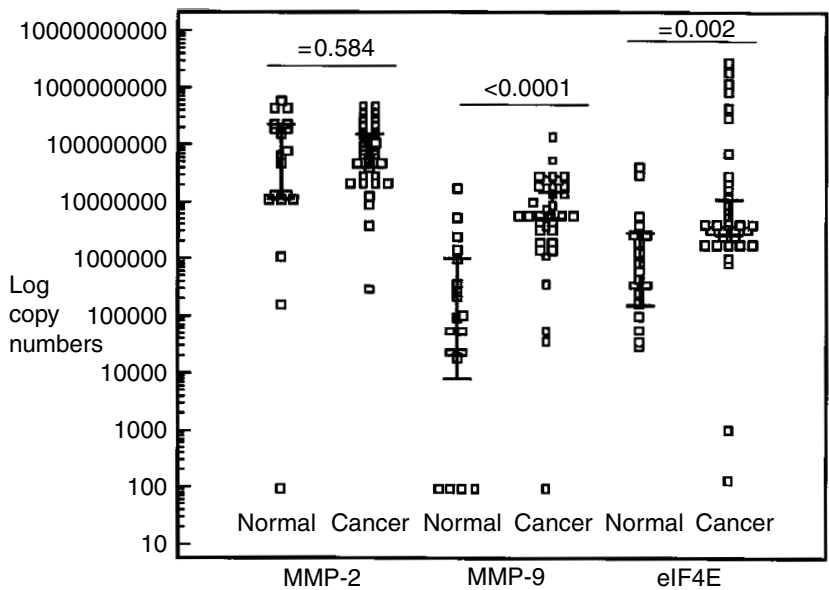

Figure I (A) Log mRNA copy numbers of the different VEGF-A splice variants in normal and malignant cervical tissue. (B) Log mRNA copy numbers of VEGF-C, b-FGF and Thrombospondin-2 in normal and malignant cervical tissue. (C) Log mRNA copy numbers of MMP-2, MMP-9 and elF-4E in normal and malignant cervical tissue. Error bar: 95\% Confidence Interval for the mean.

expressed only with MMP-2. In both normal and malignant cervical tissue, significant co-expressions were found between the 
Table 3 Spearman correlation matrix to assess gene co-expressions (with rho and $P$-values) in normal (A) and malignant (B) cervical tissue

A. Normal cervical tissue

\begin{tabular}{|c|c|c|c|c|c|c|c|c|c|c|}
\hline & & VEGF $_{165}$ & VEGF $_{|2|}$ & VEGF $_{189}$ & VEGF-C & b-FGF & TSP-2 & eIF4E & MMP-2 & MMP-9 \\
\hline$V E G F_{165}$ & $\begin{array}{c}\text { rho } \\
P \text {-value }\end{array}$ & 1.000 & & & & & & & & \\
\hline$V_{E G F_{121}}$ & $\begin{array}{c}\text { rho } \\
\text { P-value }\end{array}$ & $\begin{array}{c}0.90 \\
<\mathbf{0 . 0 0 0 1}\end{array}$ & 1.000 & & & & & & & \\
\hline$V E G F_{189}$ & $\begin{array}{c}\text { rho } \\
P \text {-value }\end{array}$ & $\begin{array}{c}0.49 \\
0.039\end{array}$ & $\begin{array}{c}0.49 \\
0.016\end{array}$ & 1.000 & & & & & & \\
\hline VEGF-C & $\begin{array}{c}\text { rho } \\
P \text {-value }\end{array}$ & $\begin{array}{c}0.81 \\
<\mathbf{0 . 0 0 0 1}\end{array}$ & $\begin{array}{c}0.77 \\
<\mathbf{0 . 0 0 0 1}\end{array}$ & $\begin{array}{c}0.63 \\
0.005\end{array}$ & 1.000 & & & & & \\
\hline b-FGF & $\begin{array}{c}\text { rho } \\
\text { P-value }\end{array}$ & $\begin{array}{c}0.83 \\
<\mathbf{0 . 0 0 0 1}\end{array}$ & $\begin{array}{c}0.64 \\
0.005\end{array}$ & $\begin{array}{c}0.32 \\
0.191\end{array}$ & $\begin{array}{c}0.83 \\
<\mathbf{0 . 0 0 0 1}\end{array}$ & 1.000 & & & & \\
\hline TSP-2 & $\begin{array}{c}\text { rho } \\
P \text {-value }\end{array}$ & $\begin{array}{c}0.86 \\
<\mathbf{0 . 0 0 0 1}\end{array}$ & $\begin{array}{c}0.77 \\
<\mathbf{0 . 0 0 0} \text { I }\end{array}$ & $\begin{array}{c}0.58 \\
0.011\end{array}$ & $\begin{array}{c}0.92 \\
<\mathbf{0 . 0 0 0 1}\end{array}$ & $\begin{array}{c}0.85 \\
<\mathbf{0 . 0 0 0 1}\end{array}$ & 1.000 & & & \\
\hline elF4E & $\begin{array}{c}\text { rho } \\
P \text {-value }\end{array}$ & $\begin{array}{c}0.56 \\
0.015\end{array}$ & $\begin{array}{c}0.39 \\
0.109\end{array}$ & $\begin{array}{c}0.26 \\
0.302\end{array}$ & $\begin{array}{c}0.48 \\
0.046\end{array}$ & $\begin{array}{c}0.66 \\
0.003\end{array}$ & $\begin{array}{l}0.063 \\
0.005\end{array}$ & 1.000 & & \\
\hline MMP-2 & $\begin{array}{c}\text { rho } \\
\text { P-value }\end{array}$ & $\begin{array}{c}0.92 \\
<\mathbf{0 . 0 0 0 1}\end{array}$ & $\begin{array}{c}0.78 \\
<\mathbf{0 . 0 0 0 1}\end{array}$ & $\begin{array}{c}0.58 \\
0.012\end{array}$ & $\begin{array}{c}0.83 \\
<\mathbf{0 . 0 0 0 1}\end{array}$ & $\begin{array}{c}0.87 \\
<\mathbf{0 . 0 0 0 1}\end{array}$ & $\begin{array}{c}0.93 \\
<\mathbf{0 . 0 0 0 1}\end{array}$ & $\begin{array}{c}0.70 \\
0.001\end{array}$ & 1.000 & \\
\hline MMP-9 & $\begin{array}{c}\text { rho } \\
\text { P-value }\end{array}$ & $\begin{array}{c}0.64 \\
0.004\end{array}$ & $\begin{array}{c}0.55 \\
0.018\end{array}$ & $\begin{array}{c}0.18 \\
0.480\end{array}$ & $\begin{array}{c}0.51 \\
0.032\end{array}$ & $\begin{array}{c}0.56 \\
0.015\end{array}$ & $\begin{array}{c}0.61 \\
0.008\end{array}$ & $\begin{array}{c}0.41 \\
0.093\end{array}$ & $\begin{array}{c}0.53 \\
0.022\end{array}$ & 1.000 \\
\hline
\end{tabular}

A strong co-expression is observed between the angiogenesis inhibitor thrombospondin-2 (TSP-2) and the other genes analysed in normal cervical tissue. $P$-values in bold represent highly significant co-expressions $(P<0.000 \mathrm{I})$.

B. Malignant cervical tissue

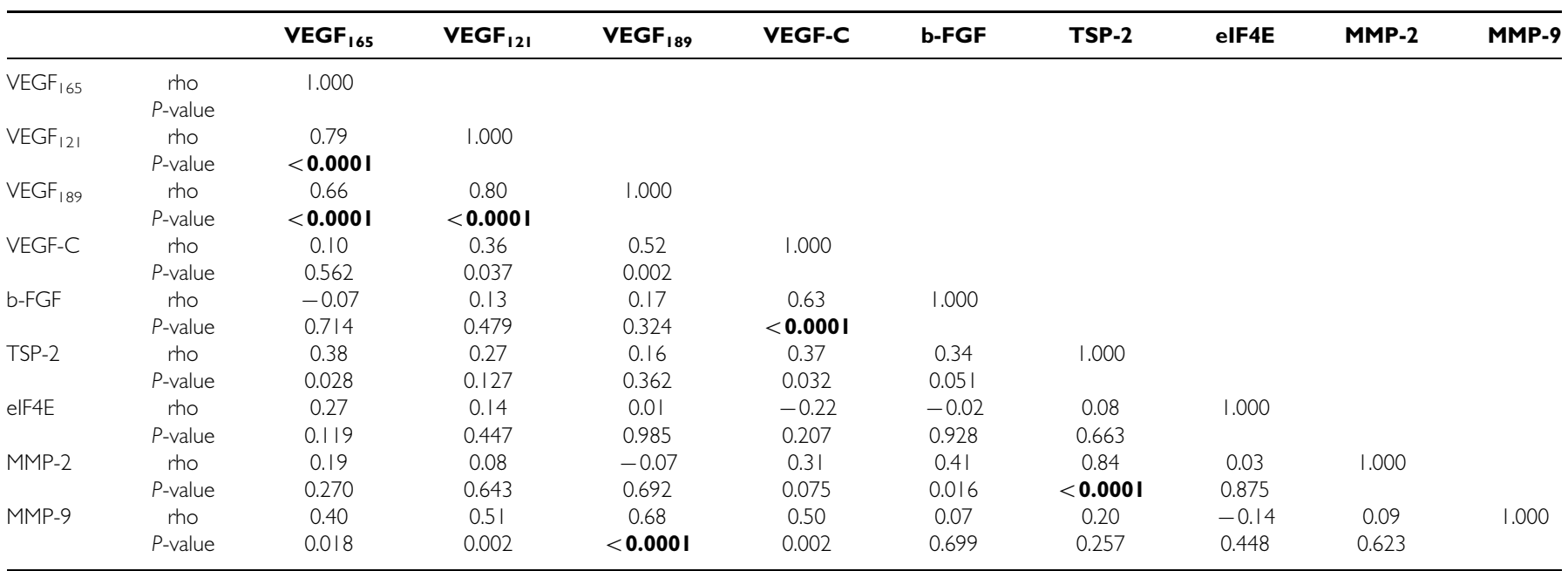

In contrast to normal cervical tissue, TSP-2 seems to be only strongly co-expressed with MMP-2 in malignant cervical tissue. The main difference between normal and malignant cervical tissue is the strong co-expression between MMP-9 and VEGF 189 in cervical cancer. $P$-values in bold represent highly significant co-expressions $(P<0.0001)$.

different VEGF-A splice variants. In normal cervical tissue, VEGF$\mathrm{C}$ is strongly co-expressed with all other genes analysed, except for MMP-9 and eIF4E. However, in cervical cancer, VEGF-C is strongly co-expressed with MMP-9, VEGF $_{189}$ and b-FGF. In addition, MMP-9 is strongly co-expressed with VEGF $_{189}$ in cervical cancer but not in normal cervical tissue.

To compare the co-expressions between the two groups (normal $v s$ malignant), the z-statistic of Fischer was used on the Spearman correlation matrices (Table 4). Of the 36 correlation coefficients, 18 $(50 \%)$ showed significant differences in favour of a higher correlation in the normal group, except for MMP-9/VEGF 189 .

Although the sample size was smaller for the normal group and the distribution (95\% confidence interval) of quantitative gene expression levels was broader, we observed a highly consistent co-expression pattern in the normal cases. This could reflect the housekeeping mode in normal cases.
Differences in gene (co-)expressions between recurrent and non-recurrent cervical cancers

Six patients (18\%) with primary cervical cancer developed recurrent disease during a mean follow-up of 27 months. Three patients were initially diagnosed with early-stage disease, the other three patients had advanced disease at initial presentation. No significant differences in co-expression patterns were found between recurrent and non-recurrent cervical cancers. However, a significant difference was found in the mean of expression levels for TSP-2, between the recurrent and the non-recurrent group $(P$-value $=0.038 ;$ Mann - Whitney $U$-test $)$. The mean value of TSP-2 in non-recurrent cases was $4.9 \times 10^{5}$ copies $\mu \mathrm{g}^{-1}$ RNA (s.d.: $+/-7.7 \times 10^{5}$ ), and in recurrent cases $1.8 \times 10^{5}$ copies $/ \mu \mathrm{g}$ RNA (SD: $\left.+/-3 \times 10^{5}\right)$. This suggests that TSP-2 might play a crucial role in progression of disease in cervical cancer. 
Table 4 Comparison of the co-expression patterns between the two groups (normal vs malignant) using the z-statistic of Fischer on the Spearman correlation matrices.

\begin{tabular}{|c|c|c|c|}
\hline Co-expression & $\begin{array}{c}\text { Correlation in } \\
\text { Normal group } \\
\text { p-value }\end{array}$ & $\begin{array}{c}\text { Correlation in } \\
\text { Cancer group } \\
\text { p-value }\end{array}$ & $\begin{array}{c}\text { z-statistic } \\
\text { rho and } \\
\text { p-value }\end{array}$ \\
\hline \multirow[t]{2}{*}{ VEGFC-VEGF 165} & 0.81 & 0.10 & 3.17 \\
\hline & $<0.000$ I & 0.562 & 0.0015 *** \\
\hline \multirow{2}{*}{ VEGFC-VEGF $F_{121}$} & 0.77 & 0.36 & 2.08 \\
\hline & $<0.0001$ & 0.037 & $0.0373^{* * * *}$ \\
\hline \multirow[t]{2}{*}{ b-FGF-VEGF 165} & 0.83 & -0.07 & 0.97 \\
\hline & $<0.0001$ & 0.714 & $0.000 I^{*}$ \\
\hline \multirow[t]{2}{*}{ b-FGF-VEGF 121} & 0.63 & 0.13 & 1.97 \\
\hline & 0.005 & 0.479 & $0.0484 * * * *$ \\
\hline \multirow{2}{*}{ TSP2-VEGF $_{165}$} & 0.85 & 0.38 & 2.76 \\
\hline & $<0.0001$ & 0.028 & $0.0058 * *$ \\
\hline \multirow[t]{2}{*}{ TSP2-VEGF 121} & 0.77 & 0.27 & 2.40 \\
\hline & $<0.0001$ & 0.127 & $0.0165 * * * * *$ \\
\hline \multirow[t]{2}{*}{ TSP2-VEGFC } & 0.92 & 0.37 & 3.66 \\
\hline & $<0.0001$ & 0.032 & $0.0003^{*}$ \\
\hline \multirow[t]{2}{*}{ TSP2-b-FGF } & 0.85 & 0.34 & 2.79 \\
\hline & $<0.0001$ & 0.051 & $0.0052 * *$ \\
\hline \multirow[t]{2}{*}{ elF-4E-VEGFC } & 0.48 & -0.22 & 2.33 \\
\hline & 0.046 & 0.207 & $0.0197 * * * * *$ \\
\hline \multirow[t]{2}{*}{ elF-4E-b-FGF } & 0.66 & -0.02 & 2.50 \\
\hline & 0.003 & 0.928 & $0.0125 * * *$ \\
\hline \multirow[t]{2}{*}{ elF-4E-TSP2 } & 0.63 & 0.08 & 2.08 \\
\hline & 0.005 & 0.663 & $0.0373 * * * *$ \\
\hline \multirow{2}{*}{ MMP2-VEGF 165} & 0.92 & 0.19 & 4.25 \\
\hline & $<0.0001$ & 0.270 & $<0.0000$ \\
\hline \multirow[t]{2}{*}{ MMP2-VEGF 121} & 0.78 & 0.08 & 2.99 \\
\hline & $<0.0001$ & 0.643 & $<0.0028$ \\
\hline \multirow[t]{2}{*}{ MMP2-VEGF 189} & 0.58 & -0.07 & 2.33 \\
\hline & 0.012 & 0.692 & $0.0198 * * * *$ \\
\hline \multirow[t]{2}{*}{ MMP2-VEGFC } & 0.83 & 0.31 & 3.58 \\
\hline & $<0.0001$ & 0.075 & $0.0003 *$ \\
\hline \multirow[t]{2}{*}{ MMP2-b-FGF } & 0.87 & 0.41 & 2.85 \\
\hline & $<0.0001$ & 0.016 & $0.0043 * *$ \\
\hline \multirow[t]{2}{*}{ MMP2-elF-4E } & 0.70 & 0.03 & 2.69 \\
\hline & 0.001 & 0.875 & $0.007 \mid * * *$ \\
\hline \multirow[t]{2}{*}{ MMP9-VEGF 189} & 0.18 & 0.68 & -2.03 \\
\hline & 0.480 & $<0.0001$ & $0.0422 * * * *$ \\
\hline
\end{tabular}

Of the 36 correlation coefficients, I 8 (50\%) showed significant differences in favou of a higher correlation in the normal group. the $P$-values of the $z$-statistic with one star show highly significant differences between the two groups, with a significant level of $0.1 \%$ ( $P$-value $<0.001$ ). These correlation coefficients are positive and only highly significant in the normal group. The two stars represent $P$-value with strong significant differences between the two correlations, with a significant level of $1 \%$ $(P$-value $<0.01)$. In all cases, correlation coefficients are positive but higher in the normal group. The $P$-values of the $z$-statistic with three stars show significant differences between the two groups with a significant level of $5 \%(P$-value $<0.05)$. Almos all correlations are positive and higher in the normal group, except for MMP9. VEGFI89.

\section{DISCUSSION}

We show here that combined application of real-time quantitative RT - PCR with correlation matrices of gene expression data allows us to identify differences in gene co-expression patterns between normal and malignant cervical tissue.

In vivo and in vitro studies using semi-quantitative techniques have recently shown that tumours exhibiting high expression levels of vascular endothelial growth factor (VEGF) have a high metastatic potential (Potgens et al, 1996; Ohta et al, 1997). In vivo studies in cervical cancer have demonstrated a significant correlation between MVD and VEGF mRNA expression, with the highest levels in stage I and stage IV disease (Fujimoto et al, 1999; Kodama et al, 1999). $\mathrm{VEGF}_{121}$ and $\mathrm{VEGF}_{165}$ were found to be the two dominant VEGF-A subtypes with similar expression levels in normal cervix as well as in cervical cancer. VEGF $_{189}$ was barely detectable. In our study, using a fully quantitative RTPCR technique, mRNA levels of the different VEGF-A splice variants were significantly higher in malignant compared to normal cervical tissues, with a more than 10-fold increase in $\mathrm{VEGF}_{121}$, $\mathrm{VEGF}_{165}$, and $\mathrm{VEGF}_{189}$. Interestingly, the highest levels of VEGF 121 , VEGF $_{165}$ and VEGF $_{189}$ mRNA were found in cervical tumours histologically characterised by lympho-vascular space involvement, which is known to be a poor prognostic factor. In normal cervical tissue, a greater distribution was observed for the mRNA copy numbers of the different VEGF-A splice variants compared to cervical cancer. This may be due in part to the influence of the hormonal cycle, however, the co-expression patterns were stronger and more consistent than in cervical cancer.

We have shown that all tumour and normal samples expressed the VEGF-A isoforms, $165>121>189$, in order of decreasing abundance. This order differs from normal and malignant breast tissue in which the $\mathrm{VEGF}_{121}$ isoform is most abundant (Scott et al, 1998). There is evidence that b-FGF mRNA levels are higher in advanced cervical cancers, regardless of histological type, suggesting that it may predominantly play a role in the later molecular events which regulate angiogenesis in this particular tumour (Fujimoto et al, 1997). Furthermore, it has been demonstrated that VEGF is essential for the initial but not continued growth of human breast carcinoma cells in vivo, and that other angiogenic factors, such as b-FGF, can substitute for VEGF during disease progression (Yoshiji et al, 1997). This is consistent with our findings that early-stage cervical cancers had no significant increase in b-FGF mRNA, whereas a significant increase was observed in advanced stage cancers. Elevated levels of eIF-4E have been associated with increased growth rates and cell transformation in HeLa cells (De Benedetti and Rhoads, 1990). It has been suggested that eIF-4E may regulate expression of genes including angiogenic factors such as VEGF and b-FGF as well as subsequent tumour growth (Kevil et al, 1996). In our study, there was a seven-fold increase in transcript level of eIF-4E in cervical cancer.

Clinical and pathological observations have revealed that lymph node involvement is one of the earliest features of metastatic disease, and this certainly holds true for cervical cancer. Bloodborne tumour cells seed out in the lymphatic hilum, and with an increasing number of tumour cells in the blood, the frequency of nodal involvement rises. This occurs particularly in patients with large volume disease and increased numbers of microvessels in the primary tumour. A second route is via lymphatic vessels, and this pathway may be of particular importance in early microdissemination to lymph nodes (Ohta et al, 2000; reviewed by Van Trappen and Pepper, 2002). It has recently been demonstrated that primary solid tumours expressing vascular endothelial growth factors -C and $-\mathrm{D}$ (VEGF-C and -D), induce lymphangiogenesis de novo, thereby providing a direct conduit for tumour cell dissemination to lymph nodes (Mandriota et al, 2001; Skobe et al, 2001; Stacker et al, 2001). In prostatic carcinoma, the expression of VEGF-C mRNA in the primary tumour is significantly higher in lymph node-positive patients compared to lymph node-negative patients (Tsurusaki et al, 1999).

Our results have revealed that VEGF-C transcript levels are more than 130-fold higher in cervical cancer compared to normal cervical tissues. Using real-time quantitative RT - PCR we found the highest VEGF-C mRNA levels in the lymph node-positive cervical cancers. Although VEGF-C is the principal lymphangiogenic growth factor described to date, it also has angiogenic properties under certain circumstances, including tumorigenesis (Olofsson et al, 1999). This implies that VEGF-C may serve to increase both tumour vascularisation and lymphangiogenesis, thereby contributing to the increase in tumour growth and the formation of metastases.

Proteolytically-mediated extracellular matrix (ECM) degradation is crucial for angiogenesis as well as for the detachment of malig- 
nant cells from the primary tumour and migration through the surrounding stroma (Pepper, 2001). Matrix metalloproteinases (MMPs) have been heavily implicated in these processes, and are indispensable for the degradation of native triple-helical collagen, a major component of ECMs. Two of the best studied MMP's in angiogenesis and cancer are MMP-2 and MMP-9 (gelatinase-A and $-\mathrm{B}$ ), which amongst other molecules degrade collagen IV, one of the major components of the basement membrane. MMP-2 and MMP-9 play an important role in triggering the angiogenic switch in null mice (reviewed by Pepper, 2001). In addition, enhanced mRNA and protein expression of both enzymes has been reported in breast, colon and pancreatic cancer (Campo et al, 1992). In our study, no differences in MMP-2 were found between normal and malignant cervical tissue at the mRNA level. However, an approximately 80 -fold increase was observed for MMP-9 mRNA in cervical cancers. The fact that we observed no increase in MMP-2 and a marked increase in MMP-9, provides no information about the status of MMP activation, which from a mechanistic point of view may be more relevant. Nonetheless, our findings have revealed a clear relationship between increased MMP-9 mRNA and cervical cancer, increasing the probability that MMP-9 plays a key role in the progression of early-stage cervical cancer.

In normal cervical tissue, gene co-expression pattern analysis revealed a strong co-expression between TSP-2, MMP-2 and the other genes analysed, except for MMP-9. In cervical cancer, TSP2 appears only to be co-expressed with MMP-2. The lymphangiogenic factor VEGF-C is strongly co-expressed with MMP-9, VEGF $_{189}$ and b-FGF in cervical cancer. In addition, MMP-9 is strongly co-expressed with $\mathrm{VEGF}_{189}$ in cervical cancer but not in

\section{REFERENCES}

Bergers G, Brekken R, McMahon G, Vu TH, Itoh T, Tamaki K, Tanzawa K, Thorpe P, Itohara S, Werb Z, Hanahan D (2000) Matrix metalloproteinase- 9 triggers the angiogenic switch during carcinogenesis. Nat Cell Biol 2: $737-744$

Campo E, Merino MJ, Liotta L, Neumann R, Stetler-Stevenson W (1992) Distribution of the 72-kd type IV collagenase in nonneoplastic and neoplastic thyroid tissue. Hum Pathol 23: 1395 - 1401

Carmeliet P, Jain R (2000) Angiogenesis in cancer and other diseases. Nature 407: $249-257$

Chomczynski P, Sacchi N (1987) Single-step method of RNA isolation by acid guanidinium thiocyanate-phenol-chloroform extraction. Anal Biochem 162: $156-159$

De Benedetti A, Harris AL (1999) eIF4E expression in tumors: its possible role in progression of malignancies. Int J Biochem Cell Biol 31: 59-72

De Benedetti A, Rhoads RE (1990) Overexpression of eukaryotic protein synthesis initiation factor $4 \mathrm{E}$ in HeLa cells results in aberrant growth and morphology. Proc Natl Acad Sci USA 87: 8212-8216

Duggan DJ, Bittner M, Chen Y, Meltzer P, Trent JM (1999) Expression profiling using cDNA microarrays. Nature Genetics 21: 10-14

Eisen MB, Spellman PT, Brown PO, Botstein D (1998) Cluster analysis and display of genome-wide expression patterns. Proc Natl Acad Sci USA 95: $14863-14868$

Ferrara N, Houck KA, Jakeman LB, Winer J, Leung DW (1991) The vascular endothelial growth factor family of polypeptides. J Cell Biochem 47: $211-$ 218

Folkman J (2000) Incipient angiogenesis. J Natl Cancer Inst 92: 94-95

Folkman J (1971) Tumor angiogenesis: therapeutic implications. N Engl J Med 285: $1182-1186$

Fujimoto J, Ichigo S, Hirose R, Sakaguchi H, Tamaya T (1997) Expression of basic fibroblast growth factor and its mRNA in advanced uterine cervical cancers. Cancer Lett 111: $21-26$

Fujimoto J, Sakaguchi H, Hirose R, Ichigo S, Tamaya T (1999) Expression of vascular endothelial growth factor (VEGF) and its mRNA in uterine cervical cancers. Br J Cancer 80: $827-833$

Hanahan D, Folkman J (1996) Patterns and emerging mechanisms of the angiogenic switch during tumorigenesis. Cell 86: $353-364$ normal cervical tissue. Comparison of the co-expression patterns between the two groups revealed that almost all correlations are positive and stronger in the normal group, except for the coexpression MMP-9/VEGF ${ }_{189}$. Recently, in vivo studies have shown that colon cancer metastasis results from an alteration in the balance between the angiogenesis inhibitor thrombospondin-2 and the angiogenic growth factor $\mathrm{VEGF}_{189}$ (Tokunaga et al, 1998). We found a significant difference in the mean of expression levels for thrombospondin-2 between recurrent and non-recurrent cancer cases, with the lowest levels in the recurrent cases. VEGF $_{189}$ has been shown to correlate with poor prognosis in colon and lung cancer (Oshika et al, 1998; Tokunaga et al, 1998), and VEGF-C may facilitate lymphatic spread (Mandriota et al, 2001; Skobe et al, 2001; Stacker et al, 2001). In our study, both VEGF $_{189}$ and VEGF-C appear to be strongly co-expressed with MMP-9 in cervical cancer but not in normal cervical tissue.

In this report, we described the combined application of fully quantitative gene expression data with correlation matrices. This approach revealed different co-expression patterns between normal and malignant cervical tissue. This combined molecular-statistical model could be applied to several other cancers or other sets of genes.

\section{ACKNOWLEDGEMENTS}

Philippe O Van Trappen was supported by the Luxembourg Cancer Foundation and the Joint Research Board of the Special Trustees of St Bartholomew's Hospital, London.

Heid CA, Stevens J, Livak, KJ, Williams PM (1996) Real time quantitative PCR. Genome Res 6: $986-994$

Houck KA, Ferrara N, Winer J, Cachianes G, Li B, Leung DW (1991) The vascular endothelial growth factor family: identification of a fourth molecular species and characterization of alternative splicing of RNA. Mol Endocrinol 5: $1806-1814$

Jeltsch M, Kaipainen A, Joukov V, Meng X, Lakso M, Rauvala H, Swartz M, Fukumura D, Jain RK, Alitalo K (1997) Hyperplasia of lypmatic vessels in VEGF-C transgenic mice. Science 276: 1423 - 1425

Kevil CG, De Benedetti A, Payne DK, Coe LL, Laroux FS, Alexander JS (1996) Translational regulation of vascular permeability factor by eukaryotic initiation factor $4 \mathrm{E}$ : implications for tumor angiogenesis. Int $\mathrm{J}$ Cancer 65: $785-790$

Kodama J, Seki N, Tokumo K, Hongo A, Miyagi Y, Yoshinouchi M, Okuda H, Kudo T (1999) Vascular endothelial growth factor is implicated in early invasion in cervical cancer. Eur J Cancer 35: 485-489

Lander ES (1999) Array of hope. Nature Genetics 21: 3-4

Liotta L, Petricoin E (2000) Molecular profiling of human cancer. Nature Reviews Genetics 1: $48-56$

Lymboussaki A, Partanen TA, Olofsson B, Thomas-Crusells J, Fletcher CD, de Waal RM, Kaipainen A, Alitalo K (1998) Expression of the vascular endothelial growth factor C receptor VEGFR-3 in lymphatic endothelium of the skin and in vascular tumors. Am J Pathol 153: 395-403

Mandriota SJ, Jussila L, Jeltsch M, Compagni A, Baetens D, Prevo R, Banerji S, Huarte J, Montesano R, Jackson DG, Orci L, Alitalo K, Christofori G, Pepper MS (2001) Vascular endothelial growth factor-C mediated lymphangiogenesis promotes tumour metastasis. EMBO 20: $672-682$

Ohta Y, Nozawa H, Tanaka Y, Oda M, Watanabe Y (2000) (Apr) Increased vascular endothelial growth factor and vascular endothelial growth factor-c and decreased nm23 expression associated with microdissemination in the lymph nodes in stage I non-small cell lung cancer. J Thorac Cardiovasc Surg 119: $804-813$

Ohta Y, Watanabe Y, Murakami S, Oda M, Hayashi Y, Nonomura A, Endo Y, Sasaki T (1997) Vascular endothelial growth factor and lymph node metastasis in primary lung cancer. Br J Cancer 76: $1041-1045$ 
Olofsson B, Jeltsch M, Eriksson U, Alitalo K (1999) Current biology of VEGFB and VEGF-C. Curr Opin Biotechnol 10: 528-535

O’Reilly MS, Boehm T, Shing Y, Fukai N, Vasios G, Lane WS, Flynn E, Birkhead JR, Olsen BR, Folkman J (1997) Endostatin: an endogenous inhibitor of angiogenesis and tumor growth. Cell 88: 277-285

O'Reilly MS, Holmgren L, Shing Y, Chen C, Rosenthal RA, Moses M, Lane WS, Cao Y, Sage EH, Folkman J (1994) Angiostatin: a novel angiogenesis inhibitor that mediates the suppression of metastases by a Lewis Lung Carcinoma. Cell 79: 315-328

Oshika Y, Nakamura M, Tokunaga T, Ozeki Y, Fukushima Y, Hatanaka H, Abe Y, Yamazaki H, Kijima H, Tamaoki N, Ueyama Y (1998) Expression of cell-associated isoform of vascular endothelial growth factor 189 and its prognostic relevance in non-small cell lung cancer. Int J Oncol 12: $541-$ 544

Pepper MS (2001) Role of the matrix metalloproteinase and plasminogen activator-plasmin systems in angiogenesis. Arterioscler Thromb Vasc Biol 21: $1104-1117$

Potgens AJ, van Altena MC, Lubsen NH, Ruiter DJ, de Waal RM (1996) Analysis of the tumor vasculature and metastatic behavior of xenografts of human melanoma cell lines transfected with vascular permeability factor. Am J Pathol 148: $1203-1217$

Schena M, Shalon D, Davis RW, Brown PO (1995) Quantitative monitoring of gene expression patterns with a complementary DNA microarray. Science 270: $467-470$

Scott PA, Smith K, Poulsom R, De Benedetti A, Bicknell R, Harris AL (1998) Differential expression of vascular endothelial growth factor mRNA vs protein isoform expression in human breast cancer and relationship to eIF-4E. Br J Cancer 77: 2120-2128

Skobe M, Hawighorst T, Jackson DG, Prevo R, Janes L, Velasco P, Riccardi L, Alitalo K, Claffey K, Detmar M (2001) Induction of tumor lymphangiogenesis by VEGF-C promotes breast cancer metastasis. Nat Med 7: $192-$ 198

Stacker SA, Caesar C, Baldwin ME, Thornton GE, Williams RA, Prevo R, Jackson DG, Nishikawa S, Kubo H, Achen MG (2001) VEGF-D promotes the metastatic spread of tumor cells via the lymphatics. Nat Med 7: 186191
Tokumo K, Kodama J, Seki N, Nakanishi Y, Miyagi Y, Kamimura S, Yoshinouchi M, Okuda H, Kudo T (1998) Different angiogenic pathways in human cervical cancers. Gynecol Oncol 68: $38-44$

Tokunaga T, Oshika Y, Abe Y, Ozeki Y, Sadahiro S, Kijima H, Tsuchida T, Yamazaki H, Ueyama Y, Tamaoki N, Nakamura M (1998) Vascular endothelial growth factor (VEGF) mRNA isoform expression pattern is correlated with liver metastasis and poor prognosis in colon cancer. $\mathrm{Br} J$ Cancer 77: $998-1002$

Tsurusaki T, Kanda S, Sakai H, Kanetake H, Saito Y, Alitalo K, Koji T (1999) Vascular endothelial growth factor-C expression in human prostatic carcinoma and its relationship to lymph node metastasis. Br J Cancer 80: 309313

Van Trappen PO, Gyselman VG, Lowe DG, Ryan A, Oram DH, Bosze P, Weekes AR, Shepherd JH, Dorudi S, Bustin SA, Jacobs IJ (2001) Molecular quantification and mapping of lymph node micrometastases in cervical cancer. Lancet 357: $15-20$

Van Trappen PO, Pepper MS (2002) Lymphatic dissemination of tumour cells and the formation of tumour micrometastases. Lancet Oncol 3: 44-52

Veikkola T, Alitalo K (1999) VEGFs, receptors and angiogenesis. Semin Cancer Biology 9: 211-220

Volpert OV, Tolsma SS, Pellerin S, Feige JJ, Chen H, Mosher DF, Bouck N (1995) Inhibition of angiogenesis by thrombospondin-2. Biochem Biophys Res Commun 217: 326-332

Yancopoulos GD, Davis S, Gale NW, Rudge JS, Wiegand SJ, Holash J (2000) Vascular-specific growth factors and blood vessel formation. Nature 407: $242-248$

Yoshiji H, Harris SR, Thorgeirsson UP (1997) Vascular endothelial growth factor is essential for initial but not continued in vivo growth of human breast carcinoma cells. Cancer Res 57: 3924-3928 